\title{
Successful endoscopic closure of a refractory button-battery tracheoesophageal fistula in a 3-year child using endoscopic submucosal dissection of the surrounding mucosa
}

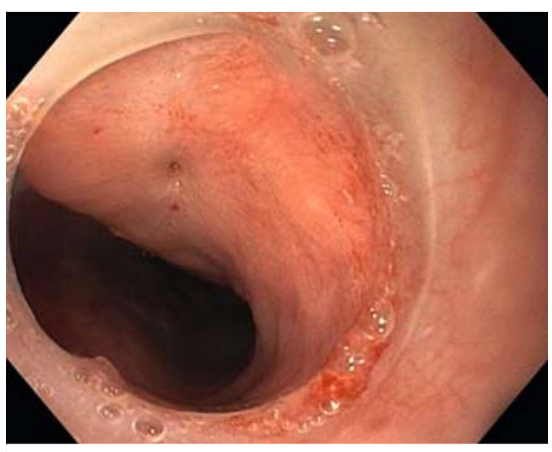

- Fig. 1 Appearance of the tracheoesophageal fistula in a 3-year-old girl after ingestion of a button battery.

Most serious button-battery ingestions are not witnessed and they can cause life threatening complications.

We present here the case of a 3-year-old girl who swallowed a button battery in January 2016 with a delayed diagnosis being made after 10 days. A 5-mm tracheoesophageal fistula was endoscopically diagnosed ( $>$ Fig. 1 ). The first attempts at closure involved the deployment of two successive esophageal covered stents between January and May ( Fig.2). The fistula decreased in size but persisted, so we then attempted controlled wound healing with a nasogastric tube, but the fistula still remained. Next, we tried a side fistula abrasion with argon plasma coagulation. Unfortunately, these techniques did not allow full recovery, even though the fistula reduced notably. After 1 year, we tried endoscopic submucosal dissection (ESD) of the mucosa surrounding the fistula, resecting a $1-\mathrm{cm}$ mucosal patch centered on the fistula. After injecting the submucosa and making the mucosal incision, we used a DualKnife (Olympus) to dissect the fibrotic area. After the dissection, the fistula was closed with three clips anchored into the submucosa of the resected area (>Fig.3; Video 1). We arranged a radiologic check with contrast, which
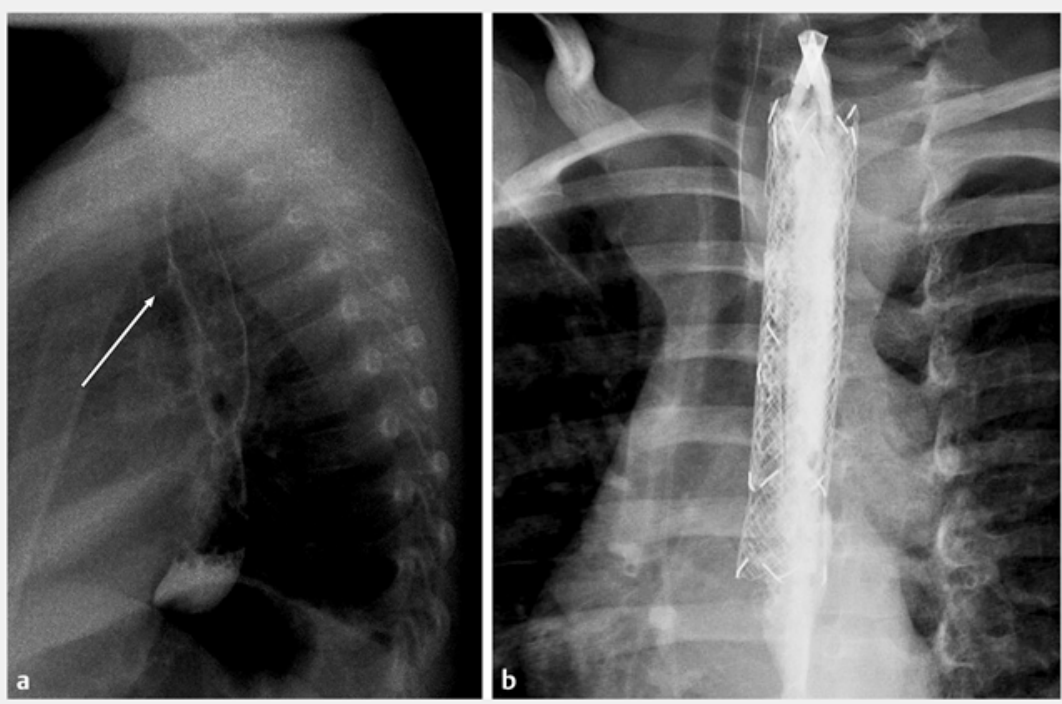

- Fig. 2 Radiographic images showing: a the fistula on a barium swallow; $\mathbf{b}$ the first attempted closure procedure with a stent positioned in the esophagus.
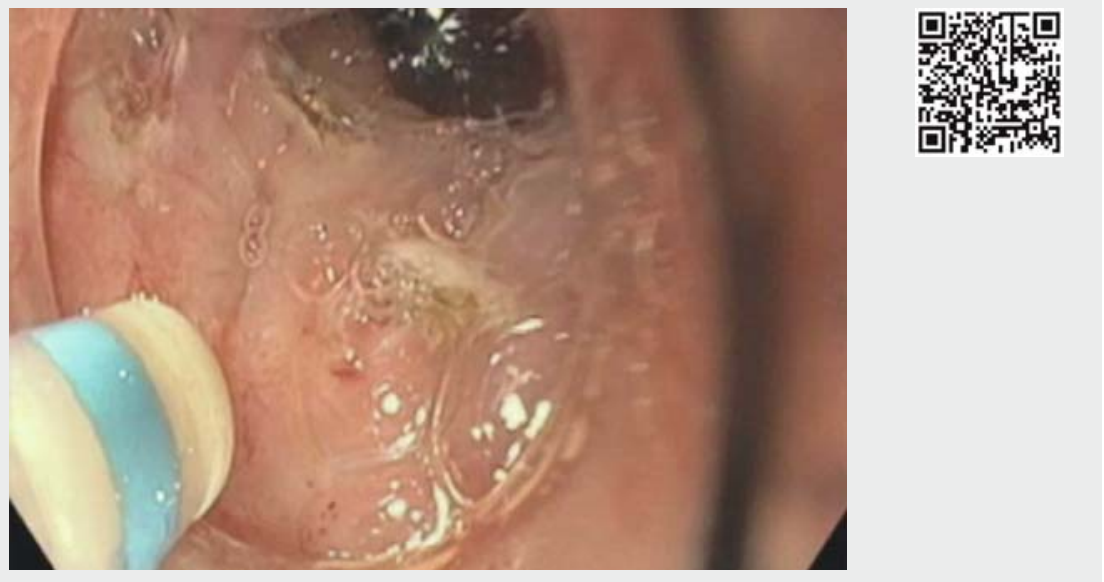

Video 1 Views of the fistula and previous attempts to close it. The endoscopic submucosal dissection procedure is performed to resect the surrounding mucosa, which is subsequently clipped to close the fistula. 

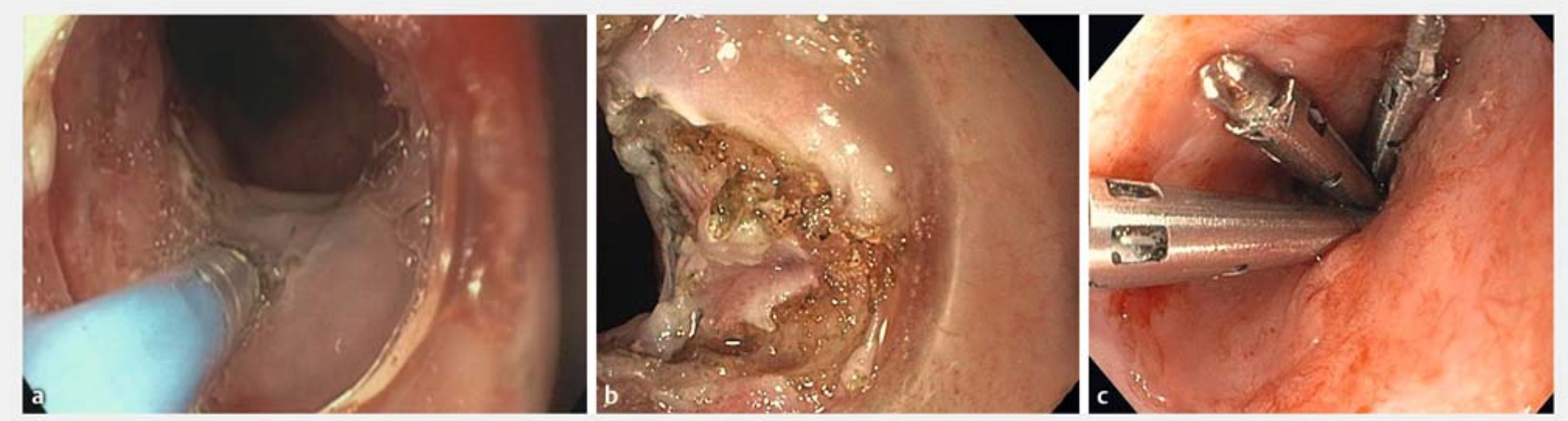

- Fig. 3 Endoscopic images showing the endoscopic submucosal dissection procedure: a the submucosal injection being performed; $\mathbf{b}$ the incision and dissection of the fibrosis; c clips placed in the submucosa.
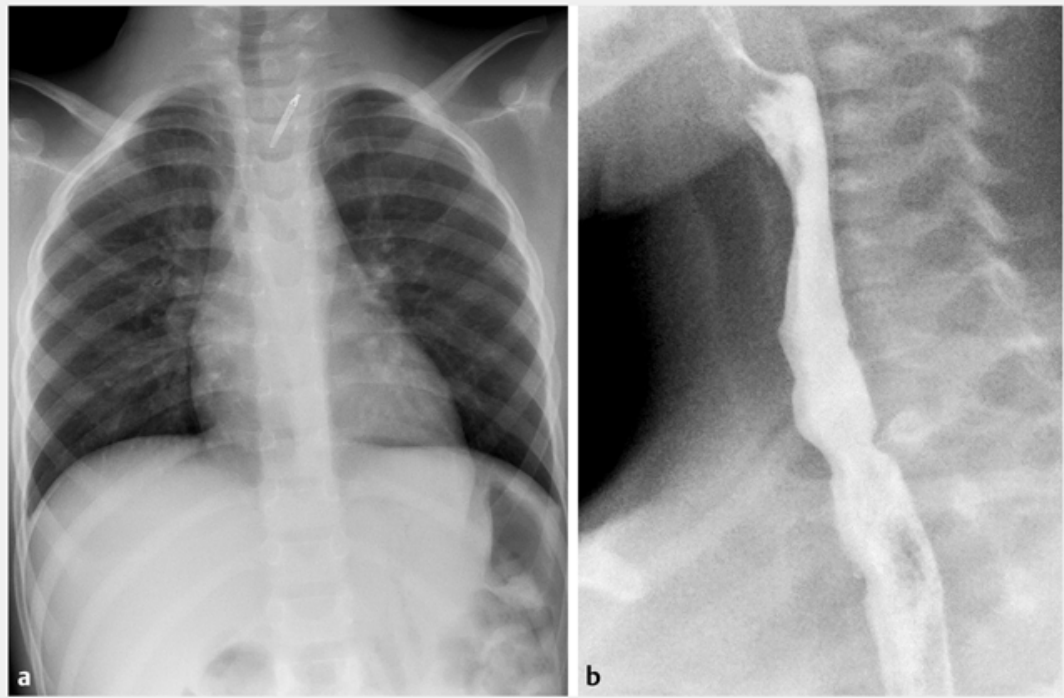

Fig. 4 Follow-up imaging. a Chest radiograph 2 weeks later. b Barium swallow 3 months later.

showed no sign of a fistula in the tracheal tract, and the girl made good and rapid progress without pain. A barium swallow 5 days later showed no signs of the fistula, and she was able to eat again. At 3 months after the procedure, a barium swallow and laryngoscopy confirmed complete healing of the fistula ( $\mathbf{F i g . 4}$ ). The current management of tracheoesophageal fistula after button-battery ingestion is not well defined and, although some studies have demonstrated the role of conservative treatment [1], the place of endoscopy is not known. In all kind of fistulas, stent placement only permits healing in 53\% [2]. ESD can be key in non-surgical treatment to achieve complete closure of such chronic fistulas, as was previously also shown by Rodriguez-Lago et al. [3].

Endoscopy_UCTN_Code_TTT_1AO_2AI

\section{Competing interests}

None
The Authors

Melissa Gruner ${ }^{1}$, Sophie Heissat ${ }^{2}$, Vincent Pitiot $^{3}$, Paul Suy ${ }^{4}$, Alain Lachaux ${ }^{2}$, Thierry Ponchon ${ }^{1,5}$, Mathieu Pioche ${ }^{1,5}$

1 Department of Endoscopy and Gastroenterology, Pavillon L, Edouard Herriot Hospital, Lyon, France

2 Department of Pediatric Endoscopy and Gastroenterology, Hôpital Femme Mère Enfant, Lyon, France

3 Department of Pediatric Digestive Surgery, Hôpital Femme Mère Enfant, Lyon, France

4 Department of Pediatric ENT, Hôpital Femme Mère Enfant, Lyon, France

5 Inserm U1032 LabTau, Lyon, France

\section{Corresponding author}

\section{Mathieu Pioche, MD}

Endoscopy unit - Digestive Disease department, Pavillon L - Edouard Herriot Hospital, 69437 Lyon, France mathieu.pioche@chu-lyon.fr 


\section{References}

[1] Grisel J], Richter GT, Casper KA et al. Acquired tracheoesophageal fistula following disc-battery ingestion: can we watch and wait? Int J Pediatr Otorhinolaryngol 2008; 72: $699-706$

[2] Silon B, Siddiqui AA, Taylor L] et al. Endoscopic management of esophagorespiratory fistulas: a multicenter retrospective study of techniques and outcomes. Dig Dis Sci 2017; 62: $424-431$

[3] Rodríguez-Lago I, Schroeven M, Rodenstein D et al. Endoscopic closure of tracheoesophageal fistula with submucosal dissection and a biosynthetic mesh. Endoscopy 2015; 47: E312-E313
Bibliography

DOI https://doi.org/10.1055/s-0043-113549

Published online: 29.6.2017

Endoscopy 2017; 49: E212-E214

(c) Georg Thieme Verlag KG

Stuttgart · New York

ISSN 0013-726X
ENDOSCOPY E-VIDEOS

https://eref.thieme.de/e-videos

回局 Endoscopy E-Videos is a free access online section, reporting 靣: on interesting cases and new techniques in gastroenterological endoscopy. All papers include a high quality video and all contributions are freely accessible online.

This section has its own submission website at

https://mc.manuscriptcentral.com/e-videos 